\title{
Supervisão de enfermagem no contexto hospitalar: uma revisão integrativa ${ }^{1}$
}

Nursing supervision in the hospital context: an integrative review

Supervisión de enfermería en el ámbito hospitalario: una revisión integradora

Juliana Ferreira de Santana CarvalhoI, Lucieli Dias Pedreschi Chaves ${ }^{\mathrm{II}}$

\section{RESUMO}

Trata-se de revisão integrativa, com objetivo de sintetizar produção científica nacional sobre supervisão de enfermagem em serviços hospitalares, de 1999 a 2010. Os dados foram coletados na base eletrônica LILACS (Literatura Latino-Americana e do Caribe em Ciências da Saúde) e registrados em instrumento específico. Foram analisadas 16 publicações que foram agrupados por similaridade de conteúdo: papel do enfermeiro supervisor, com nove artigos (56,25\%); supervisão de enfermagem e teorias administrativas com cinco artigos (31,25\%) e formação do enfermeiro supervisor com dois artigos (12,50\%). As evidências mostraram que o enfermeiro no exercício da supervisão ainda se baseia nas teorias clássicas da administração de Taylor e Fayol, caracterizada por ação controladora e punitiva, não suprindo as necessidades das equipes, pacientes e serviços de saúde. Na atualidade, espera-se que a supervisão seja feita de forma participativa, com foco na melhoria da assistência e das relações de trabalho da equipe de enfermagem hospitalar.

Descritores: Enfermagem; Supervisão de Enfermagem; Organização e Administração.

\section{ABSTRACT}

This is an integrative review, in order to synthesize the national scientific production of nursing supervision in hospital services from 1999 to 2010. Data were collected in the electronic database LILACS (Latin American and Caribbean Health Science Literature Database) and recorded on a specific instrument. It was analyzed 16 publications grouped by content similarities: the role of the nursing supervisor, nine articles (56.25\%), nursing supervision and management theories, five articles $(31.25 \%)$ and nursing supervisor formation with two articles $(12.50 \%)$. The evidence showed that the nurse in the exercise of supervision is still based on classical theories of administration of Taylor and Fayol, characterized by parent and punitive action, not supplying the needs of staff, patients and health services. Currently, it is expected that the supervision is done in a participatory manner, with focus on improvement on assistance and labor relations of hospital nursing staff.

Descriptors: Nursing; Nursing, Supervisory; Organization and Administration.

\section{RESUMEN}

Revisión integrativa con finalidad de sintetizar producción científica de enfermería referente a supervisión en servicios hospitalarios, de 1999 a 2010. Datos fueron recogidos en base electrónica LILACS (Literatura Latinoamericana y del Caribe de la Salud) y registrados en instrumento específico. Fueron analizadas 16 publicaciones agrupados por similitud de contenidos: función del supervisor de enfermeros con nueve artículos (56,25\%), supervisión de enfermería y teorías de gestión, cinco artículos (31,25\%) y el supervisor de educación en enfermería, dos artículos (12,50\%). Se evidenció que enfermeros en ejercicio de la supervisión se basa aún en teorías clásicas de administración de Taylor y Fayol, que se caracteriza por la acción de control y sanciones, no suple las necesidades de personal, pacientes y servicios de salud. En la actualidad, se espera que la supervisión sea de manera participativa, con enfoque en mejorar el servicio y relaciones laborales del personal de enfermería del hospital.

Descriptores: Enfermería; Supervisión de Enfermería; Organización y Administración.

\footnotetext{
${ }^{1}$ Trabalho de Iniciação Científica financiado pelo PIC-USP/Santander.

${ }^{\text {I }}$ Enfermeira. Brasília, DF, Brasil. E-mail: juliana_santana@hotmail.com.

II Enfermeira. Doutora em Enfermagem. Professor Doutor, Escola de Enfermagem de Ribeirão Preto, Universidade de São Paulo. Ribeirão Preto, SP, Brasil. E-mail: dpchaves@eerp.usp.br.
} 


\section{INTRODUÇÃO}

O processo de trabalho na enfermagem organiza-se em subprocessos, que podem ser denominados cuidar ou assistir, administrar ou gerenciar, pesquisar e ensinar, sendo que cada um destes possui seus próprios objetos, meios/instrumentos e atividades, coexistindo em um mesmo momento e instituição, além de ter os seus agentes, os trabalhadores de enfermagem, inseridos de forma heterogênea e hierarquizada, expressando a divisão técnica e social do trabalho(1).

Um dos instrumentos gerenciais utilizados pelo enfermeiro é a supervisão, que advém do surgimento da administração como campo específico de saber e de prática na virada do século XIX para o início do século $\mathrm{XX}$.

Nos serviços hospitalares, o enfermeiro é responsável pela gerência de unidades, atividade essa que engloba a previsão, provisão, manutenção, controle de recursos materiais e humanos e a gerência do cuidado que consiste no diagnóstico, planejamento, execução e avaliação da assistência, passando pela delegação das atividades, supervisão e orientação da equipe de enfermagem ${ }^{(2)}$.

Trata-se de um trabalho que se dá em bases coletivas e de forma interdependente, seja entre os diferentes agentes de enfermagem como entre outros profissionais da saúde. A supervisão favorece a interface entre a assistência prestada ao paciente, o trabalho da equipe de enfermagem e o contexto hospitalar no qual esta relação se insere.

À medida que conhece a estrutura do serviço e interage com a equipe da qual faz parte, o supervisor torna-se corresponsável pela manutenção de um serviço de qualidade, o que não significa prescindir da corresponsabilização dos demais atores envolvidos em determinada situação contexto organizacional ${ }^{(3)}$.

A organização do trabalho e o gerenciamento no setor saúde, especialmente no âmbito hospitalar, constituíram-se, historicamente, sob influência do modelo taylorista/fordista, da administração clássica e do modelo burocrático. Entre as principais características desses modelos destacam-se a fragmentação do trabalho com separação entre concepção e execução, o controle gerencial do processo de produção associado à rígida hierarquia, a racionalização da estrutura administrativa, a impessoalidade nas relações interpessoais e a ênfase em sistemas de procedimentos e rotinas ${ }^{(4)}$. Este modelo repercute na supervisão de enfermagem.

Com as mudanças sociais, econômicas e culturais, este padrão de gerenciamento não vem mais satisfazendo aos anseios das instituições, dos profissionais e pacientes. Os atuais modelos, marcados principalmente pela descentralização administrativa, pela criação de equipes semiautônomas, pela participação e ênfase no trabalho em equipe, têm apontado para a necessidade de adoção de métodos e estratégias que permitam a compreensão dos processos e contextos administrativos, nos quais diferentes grupos sociais encontram-se inseridos ${ }^{(5)}$.

Não basta ao enfermeiro dominar a competência técnica para a supervisão, é imprescindível o entendimento das pessoas e dos grupos, da importância das relações de trabalho na internalidade da equipe para que a supervisão seja um instrumento qualificador da prática de enfermagem.

A dimensão que os hospitais vêm adquirindo no sistema de saúde no sentido de constituir-se em serviço de saúde que centraliza ações de maior densidade tecnológica; a expressão da equipe de enfermagem hospitalar cujo trabalho impacta o cenário hospitalar e, particularmente a qualidade da assistência prestada ao paciente, o potencial da supervisão de enfermagem como espaço de interlocução e articulação entre diferentes equipes de trabalho e entre executores e planejadores do trabalho, justificaram a realização deste estudo.

$\mathrm{Na}$ perspectiva de delinear a compreensão dos aspectos relativos à supervisão de enfermagem na atualidade, e com isso, contribuir com evidências científicas para prática gerencial bem como a identificação de lacunas de conhecimento sobre a temática, questiona-se: "Qual a produção de conhecimentos científicos sobre supervisão de enfermagem em hospitais?

Face ao exposto, visando responder a essa questão foi realizado este estudo, com o objetivo de sintetizar a produção científica nacional sobre supervisão de enfermagem, em serviços de internação hospitalar, no período de 1999-2010.

\section{METODOLOGIA}

Trata-se de uma revisão integrativa de pesquisas, uma técnica que reúne e sintetiza o conhecimento produzido por meio da análise dos resultados evidenciados em estudos primários de autores especializados. O desenvolvimento deste método prevê seis etapas, que foram utilizadas para a realização do presente trabalho seguindo a estrutura clássica, a saber: 1) identificação do tema e formulação da questão norteadora, 2) busca na literatura e seleção criteriosa das pesquisas, 3) categorização dos estudos encontrados, 4) análise dos estudos incluídos, 5) interpretação dos resultados e comparações com outras pesquisas e 6) relato da revisão e síntese do conhecimento 
evidenciado nas pesquisas ${ }^{(6)}$.

Para a realização da revisão integrativa foi estabelecida a questão norteadora: "Qual a produção de conhecimentos científicos sobre supervisão de enfermagem em hospitais?".

Em seguida, foi feito o levantamento bibliográfico de artigos científicos publicados e indexados no banco de dados eletrônico LILACS, referentes à supervisão de enfermagem em serviços de internação hospitalar, no período de 1999 a 2010, utilizando o descritor: supervisão de enfermagem. A opção por este descritor deve-se ao fato de referir-se a um termo exato, situação que favorece a busca de publicações que se refiram com mais particularidade ao objeto de estudo. A opção por este banco de dados se deve a concentração de artigos nacionais e as singularidades do sistema de saúde brasileiro, dos hospitais e da prática de enfermagem nesse contexto justificam esta escolha.

Para estabelecer a amostra, foram critérios de inclusão no estudo: artigos científicos indexados no banco de dados selecionado, com o descritor em saúde elencado acima, no período de 1999 a 2010, no idioma português. Foram critérios de exclusão: artigos relacionados à normatização/legislação governamental e artigos referentes à supervisão de enfermagem na Atenção Básica.

A busca resultou em um total de 89 referências potenciais, sendo 73 delas excluídas por não atenderem aos critérios de inclusão, totalizando 16 publicações pertinentes a este estudo.

A localização dos textos na íntegra foi possível com o acesso às Bibliotecas Eletrônicas para 68,75\% dos trabalhos, Núcleo de Apoio Bibliográfico da Escola de Enfermagem de Ribeirão Preto para $25 \%$ e Biblioteca Central da Universidade de São Paulo do Campus Ribeirão Preto para os $6,25 \%$ restantes.

A partir dos resultados encontrados após a busca dos estudos na íntegra, foi realizada uma análise dos dados em duas etapas. Na primeira, utilizou-se um instrumento elaborado especificamente para este estudo, que permitia a investigação e identificação de dados como: localização do artigo, ano, periódico de publicação, autoria, objetivo, metodologia e resultados principais. Na segunda etapa, ocorreu um processo extenso de leitura na íntegra e síntese dos artigos, com o propósito de verificar a contribuição de cada estudo para a elucidação da questão norteadora, de forma a atingir o objetivo previsto.

Figura 1: Estrutura de desenvolvimento da pesquisa

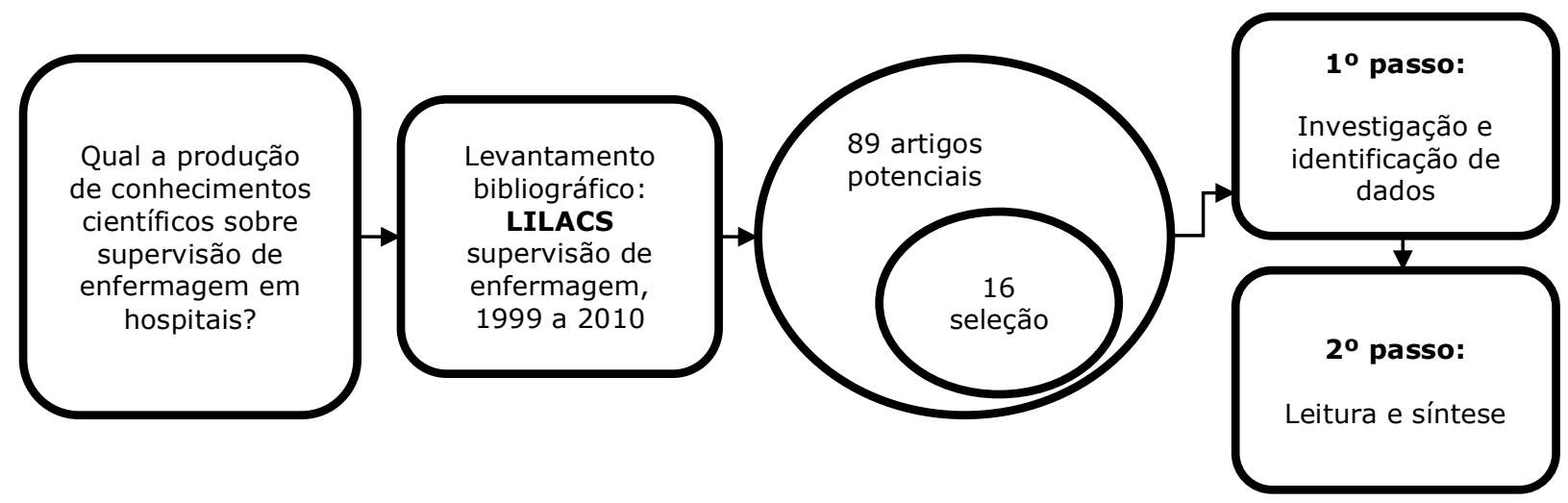

\section{RESULTADOS E DISCUSSÃO}

A leitura pormenorizada dos 16 artigos selecionados permitiu agrupar os resultados por similaridade de conteúdo, tendo constituído três categorias de análise referentes à supervisão de enfermagem no âmbito hospitalar: papel do enfermeiro supervisor, com nove artigos (56,25\%); supervisão de enfermagem e teorias administrativas, com cinco artigos $(31,25 \%)$ e formação do enfermeiro supervisor, com dois artigos (12,50\%). Cabe destacar que, de modo geral, as pesquisas na área de gerenciamento, em virtude da especificidade da temática, são do tipo descritiva, estudo de caso, relatos de experiência, afastando-se da pesquisa experimental e com baixo nível de evidência científica.

\section{Papel do enfermeiro supervisor}

Os nove artigos que compuseram esta categoria abordavam de forma geral o conhecimento dos enfermeiros acerca da supervisão. Os relatos mostram que esta função insere-se como instrumento gerencial no contexto de trabalho e apresenta-se como uma perspectiva de associação entre supervisão, aspectos de liderança, comunicação e ética.

As pesquisas evidenciam que, embora a supervisão seja prática do enfermeiro no contexto hospitalar, existe um conflito em relação à identidade do enfermeiro supervisor. 
Como relatado por diversos autores ${ }^{(5,7-9)}$, existe uma dificuldade entre os profissionais enfermeiros em identificar o trabalho de gerenciamento e de supervisão, criando uma cultura de cuidar versus gerenciar. A variação de papéis assumidos nas instituições - ora com exigências de atividades de cuidado, ora com atividades administrativas reforça essa dúvida.

Quadro 1: Distribuição dos artigos caracterizados como, papel do enfermeiro supervisor, segundo caracterização da publicação, objetivo, metodologia e principais resultados.

\begin{tabular}{|c|c|c|c|}
\hline Artigos & Objetivo & Metodologia & Principais resultados \\
\hline $\begin{array}{l}\text { Ayres JA, Berti HW, Spiri WC. Opinião e } \\
\text { conhecimento do enfermeiro supervisor sobre } \\
\text { sua atividade. } \\
\text { REME:Rev.Min.Enferm2007;11(4):407-13. }\end{array}$ & $\begin{array}{l}\text { Identificar o conhecimento } \\
\text { que o enfermeiro } \\
\text { supervisor tem sobre sua } \\
\text { atividade. }\end{array}$ & Quantitativa & $\begin{array}{l}\text { A supervisão é considerada } \\
\text { pelos enfermeiros como uma } \\
\text { atividade realizada em equipe } \\
\text { que visa à qualidade da } \\
\text { assistência. }\end{array}$ \\
\hline $\begin{array}{c}\text { Brito MJM, Lara MO, Soares EG, Alves M, Melo } \\
\text { MCOL. Traços identitários da enfermeira- } \\
\text { gerente em hospitais privados de Belo } \\
\text { Horizonte. Saude soc. } 2008 ; 17(2): 45-57 .\end{array}$ & $\begin{array}{l}\text { Analisar os traços } \\
\text { identitários de enfermeiras } \\
\text { em cargos de gerência em } \\
\text { instituições hospitalares de } \\
\text { médio e grande porte. }\end{array}$ & Qualitativa & $\begin{array}{c}\text { A enfermeira vem ocupando } \\
\text { cada vez mais espaço na gestão } \\
\text { de unidades operativas e } \\
\text { assumindo cargos } \\
\text { administrativos que exigem } \\
\text { uma visão ampliada do } \\
\text { funcionamento geral da } \\
\text { organização. }\end{array}$ \\
\hline $\begin{array}{l}\text { Galvão CM, Sawada NO, Castro AP, Corniani F. } \\
\text { Liderança e comunicação: estratégias } \\
\text { essenciais para o gerenciamento da assistência } \\
\text { de enfermagem no contexto hospitalar. Rev Lat } \\
\text { Am Enfermagem. } 2000 ; 8(5): 34-43 \text {. }\end{array}$ & $\begin{array}{c}\text { Relatar a elaboração, } \\
\text { implementação e avaliação } \\
\text { de um programa de } \\
\text { Educação Continuada sobre } \\
\text { liderança e comunicação, } \\
\text { desenvolvido com } \\
\text { enfermeiros de um hospital } \\
\text { privado. }\end{array}$ & $\begin{array}{c}\text { Quali- } \\
\text { quantitativa }\end{array}$ & $\begin{array}{c}\text { Investimento e capacitação } \\
\text { para exercício de liderança são } \\
\text { fundamentais para que o } \\
\text { profissional tente viabilizar } \\
\text { mudanças na sua prática diária. }\end{array}$ \\
\hline $\begin{array}{l}\text { Lima MADS, Gustavo AS, Coelho DF, Schmitz } \\
\text { UV, Rosa RB. Concepções de enfermeiras sobre } \\
\text { seu trabalho no modelo clínico de atenção à } \\
\text { saúde. Rev Bras Enferm. } 2000 ; 53(3): 343-54 \text {. }\end{array}$ & $\begin{array}{l}\text { Conhecer a concepção de } \\
\text { enfermeiras sobre a ênfase } \\
\text { das atividades que } \\
\text { desenvolvem no processo } \\
\text { de trabalho. }\end{array}$ & Qualitativa & $\begin{array}{c}\text { O gerenciamento é uma } \\
\text { dimensão do cuidado de } \\
\text { enfermagem e, através dele, a } \\
\text { enfermeira busca suporte } \\
\text { necessário para que se alcance } \\
\text { o produto final do processo de } \\
\text { trabalho no modelo clínico, a } \\
\text { assistência ao paciente. }\end{array}$ \\
\hline $\begin{array}{l}\text { Marcon PM, Polak YNS, Meier MJ. A Bioética no } \\
\text { processo de trabalho administrativo da } \\
\text { enfermagem: uma reflexão. Online braz j nurs. } \\
\qquad 2005 ; 4(2) \text {. }\end{array}$ & $\begin{array}{c}\text { Proporcionar aos } \\
\text { enfermeiros reflexões que } \\
\text { visem aproximar o } \\
\text { conhecimento da ética e } \\
\text { bioética ao processo de } \\
\text { trabalho gerencial da } \\
\text { profissão. }\end{array}$ & Qualitativa & $\begin{array}{c}\text { O reconhecimento da } \\
\text { importância e utilização do } \\
\text { conhecimento ético e bioético } \\
\text { na assistência, no ensino e, } \\
\text { principalmente, no } \\
\text { gerenciamento da enfermagem, } \\
\text { contribui para tomadas de } \\
\text { decisões mais adequadas }\end{array}$ \\
\hline $\begin{array}{l}\text { Martin J, Valentim A. Supervisão de } \\
\text { enfermagem x assistência ao paciente: } \\
\text { compatibilização como pressuposto à } \\
\text { identidade profissional e à qualidade da } \\
\text { assistência. Nursing } 2000 ; 26(3): 16-7 \text {. }\end{array}$ & $\begin{array}{l}\text { Refletir a dicotomia entre } \\
\text { as funções de supervisão e } \\
\text { assistência de enfermagem. }\end{array}$ & Qualitativa & $\begin{array}{c}\text { Considera-se a compatibilização } \\
\text { das funções de supervisão e } \\
\text { assistência como pressuposto à } \\
\text { construção da identidade } \\
\text { profissional, bem como a } \\
\text { prestação de serviços de } \\
\text { enfermagem de qualidade ao } \\
\text { paciente }\end{array}$ \\
\hline $\begin{array}{c}\text { Santos SR, Moreira RC. Liderança do } \\
\text { enfermeiro: desafios da prática. Online braz j } \\
\text { nurs. } 2004 ; 3(3) \text {. }\end{array}$ & $\begin{array}{l}\text { Identificar os desafios } \\
\text { enfrentados pelos } \\
\text { enfermeiros na prática } \\
\text { hospitalar com relação à } \\
\text { liderança de equipes. }\end{array}$ & Qualitativa & $\begin{array}{c}\text { A liderança e a comunicação } \\
\text { são estratégias que possibilitam } \\
\text { ao enfermeiro implementar as } \\
\text { mudanças requeridas }\end{array}$ \\
\hline $\begin{array}{c}\text { Trevizan MA, Mendes IAC, Lourenço MR, } \\
\text { Shinyashiki GT. Aspectos éticos na ação } \\
\text { gerencial do enfermeiro. Rev Lat Am } \\
\text { Enfermagem. } 2002 ; 10(1): 85-9 .\end{array}$ & $\begin{array}{l}\text { Abordar aspectos éticos na } \\
\text { ação gerencial do } \\
\text { enfermeiro }\end{array}$ & Revisão & $\begin{array}{l}\text { O enfermeiro deve promover o } \\
\text { paciente como sujeito e } \\
\text { protagonista do seu cuidado e } \\
\text { tratamento }\end{array}$ \\
\hline $\begin{array}{c}\text { Zuza DC, Silva MAPD. Estudo sobre a } \\
\text { identidade do enfermeiro em uma instituição } \\
\text { hospitalar cooperativista. } \\
\text { REME:Rev.Min.Enferm. } 2007 ; 11(4): 420-24 \text {. }\end{array}$ & $\begin{array}{l}\text { Analisar as percepções dos } \\
\text { enfermeiros em relação a } \\
\text { sua atuação em um } \\
\text { hospital cooperativista. }\end{array}$ & Qualitativa & $\begin{array}{l}\text { O enfermeiro deve usar sua } \\
\text { competência profissional para } \\
\text { determinar e planejar suas } \\
\text { atividades. Sua função } \\
\text { administrativa deverá focar a } \\
\text { assistência ao paciente. }\end{array}$ \\
\hline
\end{tabular}


Embora ainda hoje a supervisão em enfermagem seja feita seguindo os pressupostos do modelo nightingaleano e das teorias clássicas que entendem supervisionar como um ato de vigiar, fiscalizar e punir, a globalização e as mudanças no cenário sociopolítico, trás o desafio da mudança de modelo, no qual se espera que a supervisão haja como uma função de criação de estratégias de motivação, educação, desenvolvimento de pessoal e de grupo $^{(7-8)}$. Essa transformação não se faz de forma simples e ágil, requer aperfeiçoamento e mudanças em diversas áreas, tanto no âmbito dos enfermeiros que estão inseridos no mercado de trabalho, quanto daqueles que estão em processo de formação, com a incorporação de conhecimentos relativos a práticas gerenciais mais participativas e de corresponsabilização.

Para que a mudança do exercício da supervisão obtenha êxito, também se faz necessário analisar o contexto organizacional e suas articulações com as políticas de saúde, em um processo amplo que envolve planejamento, execução e avaliação. Devendo proporcionar o aprimoramento e a qualificação dos agentes de trabalho, e ainda, uma articulação política entre as esferas organizacionais e os trabalhadores ${ }^{(7)}$. É preciso difundir o conhecimento que $o$ ato de assistir não revoga $o$ de gerenciar, e vice-versa.

Toda ação gerencial, no âmbito hospitalar, deve ser fundamentada principalmente nos valores da profissão, no código de ética e nos direitos dos pacientes hospitalizados. Como valores da profissão, devem ser levados em consideração a autonomia e a atualização dos conhecimentos, a exemplo do conceito de supervisão, para que se tenha competência de atingir por meio da ação gerencial uma assistência qualificada ao ser humano ${ }^{(10-11)}$.

Nesse sentido, a liderança apresenta-se junto com a comunicação, como estratégias que possibilitam ao enfermeiro desencadear as mudanças requeridas de modo compartilhado com o grupo com o qual trabalha, utilizando de comportamentos de liderança como a iniciativa e o comprometimento com o trabalho, desenvolvendo um conhecimento comum em relação à prática profissional ${ }^{12-}$ 13).

Apesar da dificuldade para o enfermeiro reconhecer seu papel de supervisor, considerando a forma histórica como a supervisão vem sendo desempenhada, está em curso a concepção de conhecimento e atitudes para a realização de uma supervisão mais participativa, humanizada, voltada para o aprimoramento da equipe com foco na assistência de enfermagem individualizada e íntegra. Interessante destacar que, apesar do embate entre assistência e gerência, a supervisão tem potencial para articular esses dois aspectos em uma perspectiva de gerenciamento do cuidado.

\section{Supervisão e as teorias administrativas}

A Teoria da Administração Científica iniciada por Taylor fundamenta-se na aplicação de métodos da ciência positiva, racional e metódica aos problemas administrativos a fim de alcançar a máxima produtividade. A Teoria Clássica de Fayol complementou o trabalho de Taylor, substituindo a abordagem analítica e concreta de Taylor por uma abordagem sintética, global e universal. Propôs a racionalização da estrutura administrativa, e a instituição passa a ser percebida como uma síntese dos diversos órgãos que compõem a sua estrutura. A preocupação maior de Fayol é para com a direção da instituição dando ênfase às funções e operações no interior de tal. Estabeleceu os princípios da boa administração, sendo dele a clássica visão das funções do administrador: organizar, planejar, coordenar, comandar e controlar ${ }^{(14)}$.

Esses pensadores foram adotados com finalidade de garantia a melhor produtividade e não necessariamente focando aspectos de articulação e educação da equipe com foco no atendimento integral ao paciente.

Desde a $2^{\mathrm{a}}$ metade do século XIX, com o modelo proposto por Florence Nightingale na Inglaterra, a enfermagem gerencia o dia a dia das unidades assistenciais utilizando uma linha de mando vertical, formalizada e legitimada, com características das idéias de Taylor e Fayol. Porém, as estruturas verticalizadas e centralizadas, favoreceram o distanciamento e a impessoalidade entre os membros das equipes. Dessa forma, se estabeleceu uma relação hierárquica rígida e impessoal, enfraquecendo o trabalho, que se reflete em uma assistência descontínua, fragmentada e sem vínculos com os clientes.

Apesar do tempo, estes modelos, de modo geral, mantiveram-se em muitos hospitais e serviços de saúde. 
Quadro 2: Distribuição dos artigos caracterizados como Supervisão e as teorias administrativas, segundo caracterização da publicação, objetivo, metodologia e principais resultados.

\begin{tabular}{|c|c|c|c|}
\hline Artigos & Objetivo & Metodologia & Principais resultados \\
\hline $\begin{array}{c}\text { Cintra V, Sanna MC. Transformações na } \\
\text { administração em enfermagem no suporte } \\
\text { aos transplantes no Brasil. } \\
\text { Rev.bras.Enferm, 2005;58(1):78-91. }\end{array}$ & $\begin{array}{c}\text { Identificar, no período de } \\
1965 \text { a 2003, como a } \\
\text { enfermagem se } \\
\text { estruturou para gerenciar } \\
\text { a assistência de } \\
\text { enfermagem frente à } \\
\text { situação dos transplantes. }\end{array}$ & Revisão & $\begin{array}{c}\text { A enfermagem transformou o seu } \\
\text { papel gerencial inicialmente focados } \\
\text { no período intra-operatório, } \\
\text { evoluindo para o exercício da função } \\
\text { da enfermagem além dos limites } \\
\text { cirúrgicos. }\end{array}$ \\
\hline $\begin{array}{c}\text { Martins EG, Sanna MC. A produção } \\
\text { científica sobre administração em } \\
\text { enfermagem no Brasil no período de } 1947 \\
\text { a 1972. Rev.bras.enferm, 2005;58(2):235- } \\
9 .\end{array}$ & $\begin{array}{l}\text { Descrever a trajetória } \\
\text { histórica das produções } \\
\text { científicas sobre } \\
\text { administração em } \\
\text { enfermagem brasileira. }\end{array}$ & Revisão & $\begin{array}{l}\text { A enfermagem aproximou-se da } \\
\text { administração, pois percebeu a } \\
\text { importância dos princípios desta } \\
\text { ciência aplicando-os no campo da } \\
\text { saúde. }\end{array}$ \\
\hline $\begin{array}{l}\text { Servo MLS. Novo olhar... novo feixe de } \\
\text { luz... nova dimensão: eis a supervisão } \\
\text { social. Rev. Baiana.enferm } \\
2002 ; 15(1 / 2): 97-107 .\end{array}$ & $\begin{array}{l}\text { Imprimir uma dimensão } \\
\text { social, que contemple o } \\
\text { componente subjetivo e o } \\
\text { componente da razão, à } \\
\text { supervisão em } \\
\text { enfermagem. }\end{array}$ & Revisão & $\begin{array}{l}\text { A supervisão deve ser } \\
\text { instrumento/ferramenta para a } \\
\text { transformação do processo de } \\
\text { trabalho em saúde. }\end{array}$ \\
\hline $\begin{array}{c}\text { Silva MA, Erdmann AL, Cardoso RS. O } \\
\text { processo de produção administrativa da } \\
\text { enfermagem hospitalar: um sistema } \\
\text { complexo viável. REME:Rev.Min. Enferm } \\
\text { 2006;10(1):54-60. }\end{array}$ & $\begin{array}{l}\text { Descrever o processo de } \\
\text { produção administrativa } \\
\text { da enfermagem sob } \\
\text { enfoque de sistemas } \\
\text { complexos. }\end{array}$ & Revisão & $\begin{array}{l}\text { A enfermagem como sistema de } \\
\text { produção, tem produtos técnico- } \\
\text { assistenciais, mas também produz } \\
\text { atividades técnico-administrativas e } \\
\text { administrativas. }\end{array}$ \\
\hline $\begin{array}{c}\text { Spangnol CA, Ferraz CA. Tendências e } \\
\text { perspectivas da administração em } \\
\text { enfermagem: um estudo na Santa Casa de } \\
\text { Belo Horizonte-MG. Rev.Latino- } \\
\text { Am.Enfermagem } 2002 ; 10(1): 15-20 .\end{array}$ & $\begin{array}{l}\text { Analisar a forma da } \\
\text { administração em } \\
\text { enfermagem } \\
\text { desenvolvida na Santana } \\
\text { Casa de Belo Horizonte - } \\
\text { MG, tendo em vista a } \\
\text { reestruturação } \\
\text { administrativa iniciada } \\
\text { em } 1996 .\end{array}$ & Qualitativa & $\begin{array}{c}\text { Com a implementação do novo } \\
\text { Sistema de Gestão da Santa Casa } \\
\text { (SIGESC), As relações interpessoais } \\
\text { são mais valorizadas, tentando } \\
\text { diminuir os níveis hierárquicos e } \\
\text { aproximar a chefia de seus } \\
\text { colaboradores. }\end{array}$ \\
\hline
\end{tabular}

No Brasil, a partir do final década de 80 , com a implantação do Sistema Único de Saúde (SUS), e com a mudança da atuação do enfermeiro no contexto organizacional, passando a deslocar-se da área operacional para a área estratégica, ocorreu um processo de renovação, direcionado à formação de um corpo coletivo no qual a coordenação assume um papel preponderante, relativizando a hierarquia e o poder ${ }^{(15)}$.

As mudanças do sistema de saúde repercutem na necessidade da adoção de novas formas de organização dos serviços de saúde, incluindo o hospital. Na atuação do enfermeiro tem sido evidenciado que os modelos administrativos adotados, não satisfazem mais as necessidades exigidas no atual cenário hospitalar. Com as transformações constantes e complexas que ocorrem em todos os setores e com as inovações tecnológicas, os hospitais vêm buscando novas maneiras de administrar, em uma perspectiva de responsabilização coletiva, com vistas a racionalizar recursos de toda natureza e otimizar resultados, exigindo uma maneira diferente de abordagem e participação dos trabalhadores, que trazem implicações ao desenvolvimento da supervisão.

A busca dessa nova abordagem traz, no seu bojo, conceitos de flexibilidade, redução da hierarquia, trabalho em equipe e descentralização das decisões, visando à satisfação dos usuários e trabalhadores, bem como à produtividade e à responsabilidade compartilhada, que devem ser vislumbradas pelos gerentes do futuro ${ }^{(16)}$.

Nesse cenário, a supervisão se mostra um importante instrumento para a transformação do processo de trabalho em saúde, que possibilita aumentar a qualidade das intervenções de enfermagem desenvolvendo as potencialidades da equipe.

Apesar das contribuições que o modelo clássico de gerência trouxe para a organização do trabalho na área hospitalar, os conceitos contemporâneos de gerenciamento e o conhecimento da literatura mostraram que essa concepção não se adéqua mais, já que produzem efeitos negativos que prejudicam a agilidade e a operacionalização do processo de trabalho.

\section{Formação do enfermeiro supervisor}

O ensino de administração em enfermagem no processo de formação vem evoluindo ao longo do tempo, passando por transformações que refletem as mudanças sociais. No entanto, ainda é marcado como uma prática bancária com características conservadoras e autoritárias.

Por esse processo de formação acadêmica ainda não 
alcançar totalmente as perspectivas esperadas para a nova maneira de supervisionar, surge, no contexto da enfermagem, nas instituições de saúde, a educação permanente que é utilizada como mecanismo para o desenvolvimento de recursos humanos e da instituição, permitindo enfrentar e resolver os problemas, proporcionando serviços eficientes e eficazes.

Quadro 3: Distribuição dos artigos caracterizados como formação do enfermeiro supervisor, segundo caracterização da publicação, objetivo, metodologia e principais resultados.

\begin{tabular}{|c|c|c|c|}
\hline Artigos & Objetivo & Metodologia & Principais resultados \\
\hline $\begin{array}{c}\text { Munari DB, Nunes FC, Motta KAMB, } \\
\text { Esperidião E, Silva JI, Coelho MA. } \\
\text { Educação de laboratório como } \\
\text { ferramenta no processo educação } \\
\text { continuada de enfermeiros gerentes. } \\
\text { Rev.enferm. UERJ. 2008;16(4):577- } \\
83 .\end{array}$ & $\begin{array}{c}\text { Apresentar o relato de } \\
\text { experiência do } \\
\text { desenvolvimento de uma } \\
\text { Oficina de Sensibilização para } \\
\text { o Desenvolvimento de } \\
\text { Habilidades Gerenciais. }\end{array}$ & Qualitativa & $\begin{array}{l}\text { Durante o processamento das } \\
\text { experiências pessoais, a verbalização } \\
\text { possibilitou a aproximação do grupo } \\
\text { bem como a identificação entre os } \\
\text { integrantes ao compartilhar seus } \\
\text { receios, suas dificuldades de lidar. }\end{array}$ \\
\hline $\begin{array}{l}\text { Paganini MC, Suarez GG, Seiffert L, } \\
\text { Pedrozo MH, Albini RMN, Walach VR. } \\
\text { Oficinas sobre papéis e funções de } \\
\text { enfermeiras em hospital universitário: } \\
\text { relato de experiência. Cogitare } \\
\text { enferm. } 2000 ; 5 \text { (n.esp):16-24. }\end{array}$ & $\begin{array}{l}\text { Relatar os resultados de } \\
\text { quatro oficinas sobre papéis } \\
\text { e funções de enfermeiras. }\end{array}$ & Qualitativa & $\begin{array}{c}\text { Os enfermeiros realizam suas funções } \\
\text { gerenciais predominantemente } \\
\text { orientados para a tecno-burocracia } \\
\text { hospitalar. }\end{array}$ \\
\hline
\end{tabular}

Os modelos administrativos historicamente utilizados pela enfermagem tem como pressuposto a centralização de poder e do processo decisório, situação esta que muitas vezes favorece decisões pouco coerentes com a realidade dos setores de trabalho.

A mudança de modelo gerencial requer a adoção de programas educativos com foco na atividade gerencial em uma perspectiva participativa, articuladora, que favorece a participação dos trabalhadores, requer a reestruturação dos processos de trabalho nas unidades e a qualificação para a função de gestor, líder e supervisor ${ }^{(17-18)}$.

Esse processo de qualificação enfrenta dificuldades principalmente no que tange à aceitação dos superiores para a necessidade de mudanças, sobretudo no modelo de gestão de pessoas e conhecimentos ${ }^{(17)}$.

É desejável que os gerentes desenvolvam a habilidade de identificar as competências que possuem, as que precisam ser aprimoradas e as que precisam ser adquiridas. De modo geral, é necessário que o grupo de enfermeiros gerentes possua maturidade, a fim de permitir a análise de sua competência e de suas forças impulsoras e restritivas para o encaminhamento dos procedimentos de mudança no trabalho ${ }^{(19)}$.

Não há dúvida do potencial da formação e qualificação de recursos humanos, em uma perspectiva de gerar mudanças, entretanto, no que tange a supervisão de enfermagem é uma ferramenta gerencial que tem interface com o poder e, nesse sentido os processos de mudança são mais difíceis de se concretizarem, ainda assim, há que se investir na formação de enfermeiros supervisores em uma lógica diferenciada de supervisão.

\section{CONCLUSÃO}

A revisão integrativa das publicações científicas no Brasil que tratam da temática, supervisão de enfermagem no âmbito hospitalar, permitiu uma análise do histórico vivido pelos profissionais de enfermagem nesta área. Este artigo nomeia quais mudanças ocorreram, como os enfermeiros enfrentam a necessidade de atualização não só teórica como prática do gerenciamento em saúde e as dificuldades vividas nesse período de transição, fazendo uma crítica da atual situação do enfermeiro no exercício da supervisão.

O estudo das publicações selecionadas demonstrou que o enfermeiro supervisor, ainda hoje, trabalha de forma hierarquizada e tem sua atuação baseada principalmente na coordenação e no controle da equipe. Essa atuação é fundamentada principalmente nos preceitos das teorias clássicas da administração.

Alguns artigos já evidenciam a necessidade de mudança e superação destes modelos ineficientes para a realidade em que vivemos, aonde o gerenciamento deve facilitar e potencializar a qualidade do processo de cuidar.

Para isso, a supervisão de enfermagem deve ser trabalhada de forma coletiva, entre as equipes de saúde, tendo sempre como finalidade a cooperação e o estímulo do trabalhador, objetivando a melhoria da assistência ao paciente.

Para garantir esse êxito, encontramos como alternativa as atividades de educação permanente dos enfermeiros supervisores e da equipe como um todo, tendo como objeto a supervisão em uma abordagem mais participativa, com vistas a educação e não punição.

Embora os artigos abordem a inadequação do modelo 
vivido, não foram localizados artigos que abordem, de modo concreto, possibilidades e experiências exitosas de realização da supervisão com enfoque participativo e educativo da equipe de enfermagem.

A enfermagem sem dúvida tem uma grande importância na formação de estratégias para melhorar a qualidade da assistência hospitalar. A supervisão é um

\section{REFERÊNCIAS}

1. Kurcgant P. Gerenciamento em enfermagem. 1st ed. Rio de Janeiro: Guanabara Koogan; 2005.

2. Greco RM. Relato de experiência: ensinando a administração em enfermagem através da educação em saúde. Rev Bras Enferm [Internet]. 2004 [cited 2011 set 30];57(4):472-4. Available from:

http://www.scielo.br/pdf/reben/v57n4/v57n4a26.pdf.

3. Servo MLS. Pensamento estratégico: uma possibilidade para a sistematização da supervisão em enfermagem. Rev Gaucha Enferm [Internet]. 2001 [cited 2011 set 30];22(2):39-59. Available from: http://seer.ufrgs.br/RevistaGauchadeEnfermagem/article/view/4 $373 / 2326$.

4. Matos E, Pires D. Teorias administrativas e organização do trabalho: de Taylor aos dias atuais, influências no setor saúde e na enfermagem. Texto Contexto Enferm.[Internet]. 2006 [cited 2011 set 30];15(3):508-14. Available from: http://www.scielo.br/pdf/tce/v15n3/v15n3a17.pdf.

5. Brito MJM, Lara MO, Soares EG, Alves M, Melo MCOL. Traços identitários da enfermeira-gerente em hospitais privados de Belo Horizonte. Saude soc. [Internet]. 2008 [cited 2011 set 30];17(2):45-57. Available from: http://www.scielo.br/pdf/sausoc/v17n2/06.pdf

6. Ganong LH. Integrative reviews of nursing research. Res Nurs Health. 1987;10(11):1-11.

7. Ayres JA, Berti HW, Spiri WC. Opinião e conhecimento do enfermeiro supervisor sobre sua atividade. Reme: Rev. Min. Enferm. [Internet]. 2007 [cited 2011 set 30];11(4):407-13. Available from: http://www.revenf.bvs.br/pdf/reme/v11n4/v11n4a10.pdf.

8. Zuza DC, Silva MAPD. Estudo sobre a identidade do enfermeiro em uma instituição hospitalar cooperativista. Reme: Rev. Min. Enferm. [Internet]. 2007 [cited 2011 set 30];11(4):420-4. Available from: http://www.revenf.bvs.br/pdf/reme/v11n4/v11n4a12.pdf.

9. Liberali J. Dall'Agnol CM. Supervisão de enfermagem: um instrumento de gestão. Rev Gaucha Enferm [Internet]. 2008 [cited 2011 set 30];29(2):276-82. Available from: http://seer.ufrgs.br/RevistaGauchadeEnfermagem/article/view/5 592/3202.

10. Trevizan MA, Mendes IAC, Lourenço MR, Shinyashiki GT. Aspectos éticos na ação gerencial do enfermeiro. Rev Lat Am Enfermagem [Internet]. 2002 [cited 2011 set 30];10(1):85-9. Available from: http://www.scielo.br/pdf/rlae/v10n1/7776.pdf.

11. Marcon PM, Polak YNS, Meier MJ. A Bioética no processo de trabalho administrativo da enfermagem: uma reflexão. Online Braz ] Nurs [Internet]. 2005 [cited 2011 set 30];4(2). Available from:

http://www.uff.br/nepae/siteantigo/objn402marconetal.htm.

12. Santos SR, Moreira RC. Liderança do enfermeiro: desafios da prática. Online Braz J Nurs [Internet]. 2004 [cited 2011 set 30];3(3). Available from: http://www.uff.br/nepae/siteantigo/objn303santosetal.htm.

13. Santos I, Castro CB. Características pessoais e profissionais de enfermeiros com funções administrativas em um Hospital Universitário. Rev Esc Enferm USP [Internet]. 2010 [cited 2011 set 30];44(1):154-60. Available from: http://www.scielo.br/pdf/reeusp/v44n1/a22v44n1.pdf.

14. Chiavenato J. Introdução à Teoria Geral da Administração. 7th ed. Rio de Janeiro: Campus; 2007. instrumento gerencial com potencial para impactar positivamente a qualidade da assistência, entretanto, ainda hoje, um expressivo contingente de enfermeiros adota uma prática gerencial de base burocrática, ainda está distante da concepção de gerenciamento articulado/focado na assistência, prática esta que requer a adoção de medidas mais participativas e integradoras de supervisão.

15. Formiga JMM, Germano RM. Por dentro da história de administração em enfermagem. Rev Bras Enferm [Internet]. 2005 [cited 2011 set 30];58(2):222-6. Available from: http://www.scielo.br/pdf/reben/v58n2/a19.pdf.

16. Fernandes SM, Spagnol CA, Trevizan MA, Hayashida M. A conduta gerencial da enfermeira: um estudo fundamentado nas teorias gerais da administração. Rev Lat Am Enfermagem [Internet]. 2003 [cited 2011 set 30];11(2):161-7. Available from: http://www.scielo.br/pdf/rlae/v11n2/v11n2a04.pdf

17. Munari DB, Nunes FC, Motta KAMB, Esperidião E, Silva JI, Coelho MA. Educação de laboratório como ferramenta no processo educação continuada de enfermeiros gerentes. Rev. enferm. UER] [Internet]. 2008 [cited 2011 set 30];16(4):577-83. Available from: http://www.facenf.uerj.br/v16n4/v16n4a20.pdf. 18. Paganini MC, Suarez GG, Seiffert L, Pedrozo MH, Albini RMN, Walach VR. Oficinas sobre papéis e funções de enfermeiras em hospital universitário: relato de experiência. Cogitare Enferm. 2000;5(esp):16-24.

19. Motta K, Munari DB. Um olhar para a dinâmica do coordenador de grupos. Rev. Eletr. Enf. [Internet]. 2006 [cited 2011 set 30];8(1):150-61. Available from: http://www.fen.ufg.br/revista/revista8_1/atualizacao.htm.

Artigo recebido em 25.11.2010.

Aprovado para publicação em 23.09.2011.

Artigo publicado em 30.09.2011. 